sibject corroborated by an auth'stity so deservedly esteemed as Dr. Simpson, to whibth' I an disposed to awird every degree of merit whith really belongs to hiib, as having by observation and research accumulated materials to bring him to the same conclusion at which I had arrived myself. Although I feel thus thatified in having the authority of Dr. Simpson in support of this practice, I must confess that it is to the late Mr. Kinder Wood, who for many years was an active and deservedly respected colleague of mine at the Lying-in Hospital, that the merit' (if there be any) is due for first, as a modern obstetrician, adopting this practice, and also recommending it in his lectures. The practice $I$ allude to, is that of detaching and removing the placenta in cases of unaroidable hæmorrhage, attended with exhaustion. In the foregoing observations I have ventured to recommend this practice as applicable to cases in which there exist different conditions, convinced that there are many mothers scrificed by the rash mancurres which are consequent on a forced and indiscriminate delivery.

\section{HAMATURIA-POST-MORTEM-SCIRRHUS OF THE BLADDER.}

TO TAB EDITOR OF THE PBOVINCIAL MEDICAL AND Sir, SURGICAL JOURAAL.

Being a reader of your Journal, and a member of the Provincial Association, I should feel obliged by your inserting the following case, should you deem it of sufficient interest to merit a place in your columns.

$$
\text { I am, Sir, }
$$

$$
\text { Your obedient servant, }
$$

ALFRED DUNSFORD.

Culmstock, near Wellington, Somerset.

January 11, 1845.

On the 11th of July, p.m., 1843, I was summoned to Mr. J. Broom, yeoman, aged 58, of sallow complexion, and temperate habits. On my arrival, I found him labouring under severe hæmaturia, with acute pain whenever he passed his urine; no pain in the back, but a great deal orer the symphrsis pubis; the pulse full and natural; appetite good; no mucus or pus in the urine, neither was it coagulable by heat. The remedies employed were saline aperient's, mucilaginous diet and liquor potassæ in flax-seed tea, under which treatment he gradually got better and resumed his agricultural pursuits; but by some over exertion, the hæmaturia returned in about six weeks, accompanied with a frequent desire to pass his urine, and serere lacinating pain in voiding it. Copaibr, uva ursi, buchu, liquor potassæe, and opiates, were tried, but with no permanent benefit. For two or three weeks the urine would be quite clear and in great quantity, bat then the bleeding would return, and after most excruciating pain, a clot or two would pass from the urethra, the hæmaturia continuing several days similar to a periodical discharge.

On the the 9th of January, 1844, I went with him to Exeter, to consult Mr. Barnes. Mr. Barnes introduced the catheter, and, probably suspecting a calculus, sounded hin, but no stone conld be detected. His opinion was unfavourable. He ordered him to be cupped in the loins, and as the alkalies had been freely tried, wished the nitro-muriatic acid to be substituted, and subsequently the muriated tincture of iron.

No benefit was received, but from this time he gradually got worse, complaining of great pain orer the neck of the bladder; and when about to make water, he would at times throw himself on the floor, place himself in various positions, and after many attempts and agonizing pain, expel two or three clots of pure blood from the urethra. Opiates seemed to have little or no effect.

These symptoms increasing in severity, and fancying there must be some remedy, he wished me on the 31st of July to accompany him to Taunton, and have $\mathbf{M r}$. Standert's opinion. Mr. Standert passed the catheter, injected the bladder with warm water, and searched in vain for a stone; a little bloody urine dribbled away. Balsam of copaiba, leeches to the perineum, decoction. of matico, with mucilage, were ordered ; but all availed nothing.

My patient, still getting worse, was now compelled to remain in bed : incontinence of urine took place, and about two months previous to his death, a small quantity of mucus, mixed with blood, was observable in the urine for the first time. He lingered until the 10th of January, 1845, when he died about one o'clock p.m.

Assisted by my friend, Mr. R. Alford, of Seaton, we proceeded to a post-mortem examination, about twelve hours after death, when the results were as follows:-

Left kidney pale and flaccid, about the natural size, with its pelvis and ureter enormonsly distended with urine; ureter large enough to contain a mould candle; texture of the kidney pale, otherwise healthy. Right kidney three times its natural size; pale and somewhat indurated, containing small abscesses, the ascending colon bound down to it by strong adhesions; ureter similarly distended to the other. Bladder one solid mass of scirrhus, most hardened at its fundus, some part ossified ; its cavity so obliterated and so small that it would not contain two drachms of urine. Prostate partook of the scirrhus. Liver and other viscera healthy.

The hæmaturia most probably was the result of the scirrhus, but with so much disease of the right kidney, I cannot account for the abscence of pain in the lumbar region, numbness of the thigh, and romiting, such prominent symptoms in nepbritic affections.

\section{PROVINCIAL \\ Ftedical \& Eurgical Journal.}

WEDNESDAY, JANUARY 22, 1845.

According to the promise given in the last number of the Journal, we this week give insertion to the important document communicated by the Society of Apothecaries, and beg to direct attention to it, in order that the necessary information requested may as shortly as practicable be obtained. We may take this occasion to observe that,although the gross misrepresentations, made and circulated from the worst of motives, of the course pursued by the Provincial Medical and Surgical Association, 